\title{
SPRAYSAFE MANAGER: A DECISION SUPPORT SYSTEM FOR AERIAL APPLICATION OF HERBICIDES IN FORESTRY
}

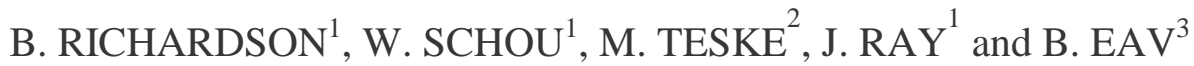

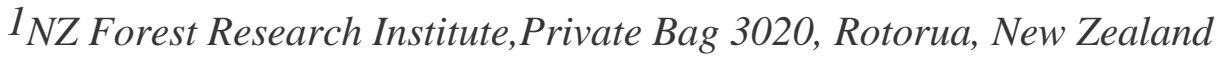 \\ ${ }^{2}$ Continuum Dynamics Inc., PO Box 3073, Princeton, NJ, 08543, USA \\ ${ }^{3}$ USDA Forest Service, FHTET, 3825 E. Mulberry St., Ft. Collins, CO, 80524, USA
}

Herbicides provide a valuable vegetation management tool for forest managers. Concerns about environmental impacts of herbicides has led to increased regulatory, accountability and quality control demands, particularly with respect to aerial application. Calculation or assessment of risk from herbicides requires an estimate of the expected level of exposure. The development of validated aerial application simulation models has for the first time provided applicators and regulators with a reliable method of calculating exposure, and their use provides a means to mitigate adverse effects. However, there has been no simple method for interpreting exposure data in a biologically meaningful way. SpraySafe Manager, a collaborative New Zealand Forest Research Institute and USDA Forest Service project, has addressed these problems by integrating an aerial application simulation model (Forest Service Cramer-Barry-Grim) with models of plant response to herbicide application. The system calculates the width of buffer or no-spray zones necessary to ensure damaging levels of herbicide do not drift onto adjacent sensitive plant species. The effects of varying application techniques or weather conditions can also be simulated. With a simple, userfriendly interface, SpraySafe Manager allows users to rapidly determine biological and economic consequences of aerial application scenarios.

\section{VISUALISATION BY CONFOCAL LASER SCANNING MICROSCOPY OF STOMATAL INFILTRATION OF SURFACTANT SPRAYS INTO LEAVES}

\author{
R.E. GASKIN, R.J. MURRAY and J.A. ZABKIEWICZ \\ NZ Forest Research Institute Ltd, Private Bag 3020, Rotorua
}

The ability of organosilicone surfactants to induce stomatal infiltration of spray solutions into foliage, by virtue of their low surface tensions, is well established. Stomatal infiltration can be observed microscopically with the aid of fluorescent dyes, or determined by measuring uptake of radiolabelled compounds immediately upon application to leaves. However, the reasons for an apparent lack of stomatal infiltration in certain species (eg. grasses), despite the presence of numerous fully-open stomata, has not been elucidated. Confocal laser scanning microscopy is a relatively new technique which can be used to reveal internal structures of biological samples in vivo, without the need for complicated preparation procedures. It has been used now to investigate the nature of stomatal infiltration of organosilicone solutions. The technique provides a new "real-time" approach to the study of stomatal infiltration and has revealed some novel explanations for apparent differences between species. High levels of stomatal infiltration occur in bean due to rapid diffusion of liquid out of the sub-stomatal cavity into mesophyll cells. In contrast, the apparent low levels of infiltration into wheat stomata are due to liquid being contained within the sub-stomatal cavity, with no short-term movement into adjacent cells. Differences in the cuticles lining the walls of sub-stomatal cavities in the two species are implicated. 